\author{
GERALD F. GIFFORD, ROBERT H. FAUST, AND GEORGE \\ B. COLTHARP
}

Highlight: Several instruments used for measuring soil compaction have been evaluated on a homogeneously-textured, nongravelly silt-loam soil. The instruments used in the study were the air permeameter, proving ring penetrometer, volumeasure, pocket penetrometer, and gamma ray scattering device. Correlation coefficients and regression equations were developed between each instrument and bulk density as determined by the soil core method. Readings from all instruments were significantly correlated with soil core bulk density.

The two instruments which had the highest correlation with bulk densities during initial testing, the air permeameter and the proving ring penetrometer, were further evaluated on a rangeland soil. In this instance, predicted bulk densities (using the above regression equations) from air permeameter readings correlated better with soil core bulk densities than did predicted bulk densities from proving ring penetrometer readings.

Measurement of soil compaction is often a problem on both agricultural lands and wildlands. Compaction of the mineral soil fraction in surface soils has important hydrologic implications in terms of reduced infiltration rates and subsequent impacts on plant growth. For example, trampling by livestock and big game animals may cause compaction of both forest and rangcland soils. Compaction is most severe in the spring when the soil is moist, or after heavy rainfalls. With increased soil compaction, surface runoff potentials are increased, erosion potentials may be increased, and given sufficient time, plant composition and cover may change.

Compaction is usually measured in terms of the severity of soil compression. However, before compression can be measured, reliable instruments are needed to measure the degree of soil compaction. The two objectives of this study were: (1) To determine the correlation between several soil compaction-measuring instruments and (2) to evaluate and compare the performance of various instruments under controlled and actual grazing conditions.

\section{Methods and Procedure}

\section{North Logan Study Area}

For initial compaction tests, a nongravelly, homogeneous silt loam soil was selected. The study area was $27 \mathrm{~m} \times 14 \mathrm{~m}$ and was fenced to exclude animals. In the spring of 1968 , the site was rototilled twice to a depth of 2.4 to $3.2 \mathrm{~cm}$, vegetation in the form of grass clumps and

Authors are associate professor rangeland hydrology, graduate research assistant, and associate professor rangeland hydrology, Watershed Science Unit, Range Science Dep., Utah State University, Logan 84322. Dr. Coltharp is currently associate professor of forestry at the Univ. of Kentucky and Mr. Faust is currently with the U.S. Forest Service.

This research was in cooperation with the Utah Agricultural Experiment Station, Project 749. Journal paper 2187, Utah Agr. Exp. Sta., Logan 84322. sizeable roots was raked out of the plots, and each plot was rolled with a lawn roller. The completely randomized design called for 32 plots, each $1.7 \mathrm{~m} \times 1.7 \mathrm{~m}$. Four treatments (a control [unpacked, except for lawn roller], a light, a medium, and a heavy compaction treatment) were used with each treatment replicated eight times. Within each plot were four subplots $(0.8 \mathrm{~m} \times 0.8 \mathrm{~m})$ and four samples were taken within each subplot. In all, 16 samples were taken with each instrument on each of the 32 plots for a total of 512 samples per instrument.

A gasoline-driven soil tamper was used to compact the soil. The control plots were unaltered, the light treatment plots received two passes with the soil tamper, the medium treatment plots received four passes, and the heavy treatment plots received six passes. After the tamping treatment, the plots were again rolled. The plots were then watered with gentle spray from a fire hose. When the top $0.6 \mathrm{~cm}$ of soil was wet, the plots were allowed to drain overnight. The next day they were sampled.

\section{Eureka Study Site}

To evaluate soil-compaction measuring instruments on rangeland, a site 9 miles south of Eureka, Utah, was selected. Twenty-six seeded experimental pastures were available and were being grazed by sheep, cattle, or a combination of both at various stocking rates. Each pasture (28-32 ha) contained an ungrazed exclosure ( $0.4 \mathrm{ha})$, and, in addition, a native range pasture ( $240 \mathrm{ha}$ ) had been fenced.

Pastures 6, 7, 14, and 17 were selected for sampling because of similarity in grass species and sheep grazing intensities. Pastures 6 and 7 were seeded with intermediate wheatgrass (Agropyron intermedium). Pastures 14 and 17 were seeded to crested wheatgrass (Agropyron cristatum). Pastures 6 and 14 had been grazed heavily by sheep while pastures 7 and 17 had been grazed lightly by sheep.

The four grazing units were sampled twice, first in the spring of 1968 (March 30 and April 13) before the livestock went on the grazing units, the second in the summer of 1968 (July 24 and August 8) after the livestock had been removed.

The proving ring penetrometer, the air permeameter, and the Uhland soil core sampler were utilized at the Eureka site. Each pasture was divided into four quadrants for sampling. Within each quadrant, 25 samples were taken with the proving ring penetrometer, 25 samples with the air permeameter, and 5 samples with the Uhland soil core sampler. Two transect lines were established in each quadrant, and the sampling sites were taken at random along these lines. To reduce the effects of soil variability at each sampling point, air permeameter, proving ring penetrometer, and soil core readings were all taken within $20 \mathrm{~cm}$ of each other. Sampling procedures in the untreated native pasture were similar. Within the exclosure in each pasture the 25 sampling sites were chosen at random.

Soil moisture during the first sampling period was high because of spring precipitation in the form of rain and some snow. During the summer sampling periods, the soil was again kept moist by frequent thunderstorms. For this reason, the soil moisture content during each sampling period was comparable. 


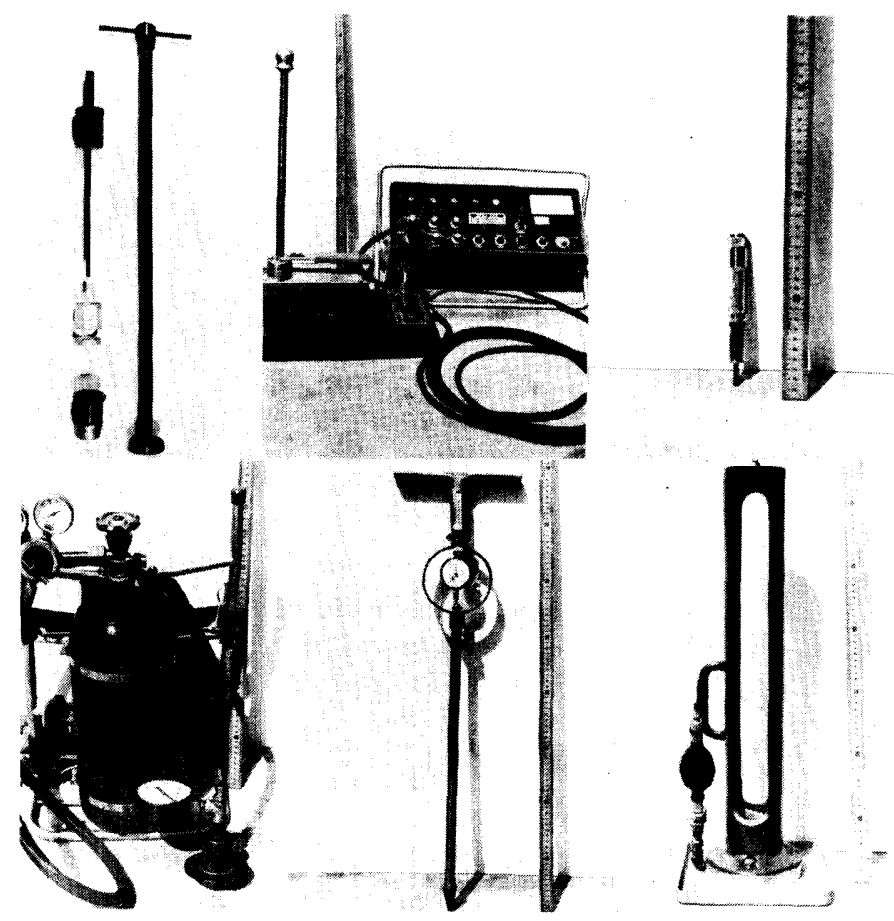

Fig. 1. (Top row, left to right) Uhland soil sampler, gamma ray scattering device, pocket penetrometer. (Bottom row, left to right) Air permeameter, proving ring penetrometer, and volumeasure.

\section{Description of the Instruments}

Description and operation of the six instruments evaluated are as follows.

\section{Soil Core Sampler}

The Uhland sampler (Fig. 1) extracts cores $7.5 \mathrm{~cm}$ in diameter $\times$ $7.5 \mathrm{~cm}$ deep (Hoover et al. 1954). Use of soil core samplers is well covered in the literature (Coile 1936; Jamison et al. 1950; Smith 1951; Andrews and Broadfoot 1957; Smith and Larson 1959; Fox and PageHanify 1959; Van Groenewoud 1960; Zwolinski and Rowe 1966).

\section{Pocket Penetrometer}

The pocket penetrometer is an instrument designed for use by road engineers and soil scientists (Soiltest, Model CL-700). The penetrometer is $2.4 \mathrm{~cm}$ long and weighs about $230 \mathrm{~g}$ (Fig. 1). The instrument registers (in $\mathrm{kg} / \mathrm{cm}^{2}$ ) the weight required to push the tip of the instrument into the soil to a depth of $0.3 \mathrm{~cm}$. Use of various penetrometers have been discussed by Richards (1941), Shaw et al. (1942), Watson (1951), Terry and Wilson (1953), Vomocil (1957), Carter (1967), and Thompson (1968).

\section{Proving Ring Penetrometer}

The proving ring penetrometer (Soiltest Model CN-970) consisted of a cone, shaft, and proving ring with a dial indicator (Fig. 1). The resistance of a soil to the cone penetration causes the proving ring to distort, which, in turn, causes the indicator on the dial to move. The force required to push the cone into the ground $3.2 \mathrm{~cm}$ is then read from the dial. A calibration curve is used to convert the dial reading into load (expressed in pounds).

\section{Volumeasure}

The Volumeasure (Soiltest, Model CN-980) is composed of a density plate, graduated glass cylinder and guard, and pressurevacuum bulb with control valve (Fig. 1).

In calculating soil density, volume of a hole is determined essentially by the quantity of water (contained within a flexible rubber container) needed to completely fill the hole. The weight of the soil removed from the hole is then determined. Bulk density is calculated by dividing weight by volume. Variations of the method are discussed by Israelson (1918), Beckett (1928), Curry (1931), Lutz (1944), and McClintock (1959).

\section{Air Permeameter}

The air permeameter consists of an air cylinder, regulator, toggle air valve, pressure gauge, and soil cup (Fig. 1). The soil cup has an outside diameter of $4.3 \mathrm{~cm}$ and penetrates the soil to a $2.5 \mathrm{~cm}$ depth. The cup is pushed into the ground until the flange around the cup is in contact with the soil surface. The resistance of the soil to the air causes a back pressure, which is then read off the pressure gauge, and recorded. Air permeameters have been discussed by Torstensson and Erickson (1936), Russell and Balcerck (1944), Evans and Kirkham (1949), Wilde and Steinbrenner (1950), Tanner and Wengel (1957), Steinbrenner (1959), and Tueller (1962).

\section{Gamma Ray Scattering Device}

The gamma ray scattering device (Troxler Model SC-120H) is a soil density gauge with a radioactive source consisting of 3 millicuries of radium-beryllium (Fig. 1). For operation, the probe is lowered into a hole about the size of the rod. Gamma rays are emitted into the soil. The density of the soil weakens and transforms the emitted gamma photons into slowed gamma photons. These photons are detected in the gauge and recorded by the scaler. The reading is then adjusted for soil moisture and the density of the soil is read from a calibration curve. This technique has been discussed by Vomocil (1954a, 1954b), Van Bavel et al. (1957), Phillips et al. (1959), Phillips (1960), Phillips and Brown (1966), and Taylor and Kansara (1967).

\section{Results and Discussion}

\section{North Logan Study Area}

Bulk density values from the soil cores (Table 1) show that there was a difference in the four sampling treatments applied. The greatest difference was between the control and heavy treatment, though differences were small among the light, medium, and heavy treatments. To produce greater differences, more passes with the soil tamper would have been desirable on the medium and heavy treatments.

\section{Proving Ring Penetrometer Samples}

Because the proving ring penetrometer measures soil com-

Table 1. Means and standard deviations of the various compaction measures on the North Logan study plots. ${ }^{1}$

\begin{tabular}{|c|c|c|c|c|c|c|c|c|c|c|}
\hline \multirow[b]{3}{*}{ Variables } & \multicolumn{10}{|c|}{ Compaction treatment } \\
\hline & \multicolumn{2}{|c|}{ Control } & \multicolumn{2}{|c|}{ Light } & \multicolumn{2}{|c|}{ Medium } & \multicolumn{2}{|c|}{ Heavy } & \multicolumn{2}{|c|}{ Combined } \\
\hline & mean & $\mathrm{sd}^{2}$ & mean & sd & mean & sd & mean & sd & mean & sd \\
\hline Soil core bulk density (gms/cc) & $1.06^{a}$ & 0.04 & $1.22^{b}$ & 0.04 & $1.27^{c}$ & 0.03 & $1.29^{c}$ & 0.03 & 1.21 & 0.01 \\
\hline Gamma ray scattering device (gms/cc) & $1.73^{a}$ & 0.11 & $1.57^{b}$ & 0.09 & $1.54^{b}$ & 0.09 & $1.56^{b}$ & 0.13 & 1.60 & 0.13 \\
\hline Volumeasure $(\mathrm{gms} / \mathrm{cc})$ & $1.08^{a}$ & 0.08 & $1.20^{b}$ & 0.09 & $1.23^{b}$ & 0.09 & $1.24^{b}$ & 0.12 & 1.19 & 0.12 \\
\hline Proving ring penetrometer (load in pounds) & $22.16^{a}$ & 0.76 & $66.46^{b}$ & 1.49 & $97.58^{c}$ & 1.73 & $115.77^{d}$ & 2.14 & 75.49 & 3.90 \\
\hline Air permeameter (pounds back pressure) & $2.30^{a}$ & 0.82 & $6.52^{b}$ & 1.72 & $8.72^{c}$ & 1.60 & $10.12^{d}$ & 1.40 & 6.91 & 3.28 \\
\hline Pocket penetrometer $\left(\mathrm{kg} / \mathrm{cm}^{2}\right)$ & $0.83^{a}$ & 0.19 & $1.87^{b}$ & 0.49 & $2.59^{c}$ & 0.73 & $3.11^{d}$ & 0.84 & 2.10 & 1.05 \\
\hline
\end{tabular}

${ }^{1}$ Any means within a given row with the same letter are not significantly different at the .05 level of probability.

${ }^{2} \mathrm{sd}=$ standard deviation. 

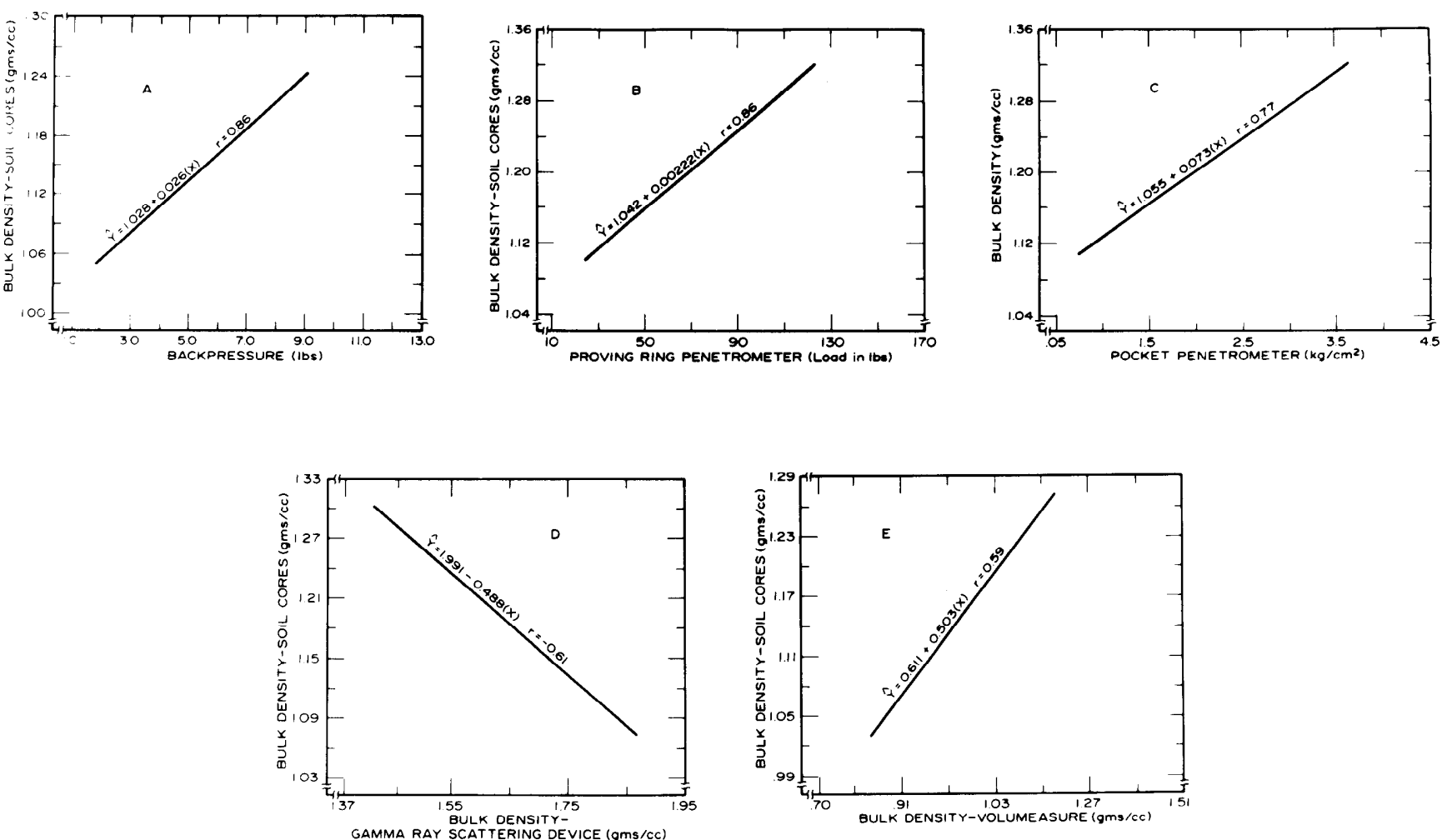

Fig. 2. Linear regressions for predicting bulk density using the various instruments shown in Figure 1 .

paction in terms of pounds and not gms/cc, a linear regression equation was developed to predict bulk density. Pooling data for all treatments yielded a regression equation $\hat{Y}=1.042+.002 X$ (Fig. 2B). Despite the fact that soil moisture, bulk density, presence of small gravel, and root and worm channels all influence penetrometer readings, the correlation $(r=0.86)$ is significant at the .01 level of probability.

\section{Pocket Penetrometer}

The linear regression equation for predicting bulk density from soil compaction readings in $\mathrm{kg} / \mathrm{cm}^{2}$ is shown in Figure $2 \mathrm{C}$. Though the correlation coefficient was 0.77 (significant at .01 level of probability), the pocket penetrometer was deemed a difficult instrument to use under field conditions. Examples include difficulty in accurately reading the scale, the small sampling area of th $0.3-\mathrm{cm}$-diameter tip, problems with crusting of the soil surface and accurately determining when the tip has penetrated the soil the required $0.3 \mathrm{~cm}$.

\section{Volumeasure}

Of all the instruments tested, the volumeasure values showed the poorest correlation $(r=0.59$; significant at .01 level of probability) with soil core bulk density. However, the volumeasure and soil cores gave similar mean bulk density values (Table 1). Difficulties in using the instrument include possible loss of soil when digging the hole, reading the meniscus on the glass cylinder, and determining when the water has reached the lowest level in the cylinder as water enters the hole.

\section{Air Permeameter}

The linear regression equation for predicting bulk density from pounds of back pressure is shown in Figure 2A. The correlation coefficient $(r)$ between back pressure and bulk density (from soil cores) was 0.86 (significant at .01 level of probability). Problems in using the instrument can result when soil moisture is high (back pressure becomes higher than normal) or if the soil cup is not correctly pushed into the ground.

\section{Gamma Ray Scattering Device}

The gamma ray scattering device measures the inverse of the soil core bulk density (Fig. 2D; $r=-0.61$; significant at .01 level of probability). Taylor and Kansara (1967) attribute this inverse relationship to greater scattering and absorption of the gamma photons as the soil density increases. Since soil moisture increases the occurrence of photon slowing, each reading was corrected for soil moisture. A major problem in the practical use of the instrument was that readings could not be taken at a soil depth of less than $10 \mathrm{~cm}$. All the other instruments measured soil compaction in the surface $5 \mathrm{~cm}$.

\section{Eureka Study Area Composition Measures}

Bulk density estimated (using the regression equations shown in Fig. 2) from the air permeameter and proving ring penetrometer closely matched the bulk density obtained from the soil cores at the Eureka study site. In fact, most of the instrument deviations from the actual bulk density were small. Both the air penetrometer and the proving ring penetrometer had average deviations of $0.049 \mathrm{gms} / \mathrm{cc}$ (extreme deviations were 0.11 and $0.14 \mathrm{gms} / \mathrm{cc}$ for the two instruments, respectively). Table 2 shows the correlations between bulk density $(\mathrm{gms} / \mathrm{cc})$, the air permeameter (lb back pressure), and the proving ring penetrometer (lb). These correlations were made using combined data from both sampling periods. Bulk densities predicted from air permeameter readings had higher correlations with actual bulk densities than did bulk densities predicted from the proving ring penetrometer. The capability of these instruments to estimate bulk density within 0.04 to $0.05 \mathrm{gms} / \mathrm{cc}$ is notable.

It may be concluded that the air permeameter and proving ring penetrometer can be used to obtain estimates of soil 
Table 2. Correlation coefficients ( $r$ values) between predicted bulk densities using the air permeameter and the proving ring penetrometer and actual bulk densities (as determined from soil cores) as obtained from combining the observations from the pastures, exclosures, and native rangeland units at the Eureka study site. All correlation coefficients are significant at the .01 level of probability.

\begin{tabular}{lcccc}
\hline \hline & $\begin{array}{c}\text { Pasture } \\
(\mathrm{n}=200)\end{array}$ & $\begin{array}{c}\text { Exclosure } \\
(\mathrm{n}=40)\end{array}$ & $\begin{array}{c}\text { Native } \\
\text { rangeland } \\
(\mathrm{n}=64)\end{array}$ & $\begin{array}{c}\text { Combined } \\
\text { Combined } \\
(\mathrm{n}=304)\end{array}$ \\
\hline $\begin{array}{l}\text { Bulk density vs } \\
\text { air permeameter }\end{array}$ & 0.65 & 0.63 & 0.52 & 0.66 \\
$\begin{array}{l}\text { Bulk density vs } \\
\text { proving ring penetrometer }\end{array}$ & 0.37 & 0.47 & 0.46 & 0.47 \\
\hline
\end{tabular}

compaction on rangelands, particularly if the soil density (without gravel) is between 1.06 to $1.29 \mathrm{gms} / \mathrm{cc}$.

\section{Summary and Conclusions}

The present study evaluated several instruments for measuring compaction on a homogeneous nongravelly soil. The instruments were the air permeameter, proving ring penetrometer, volumeasure, pocket penetrometer, and gamma ray scattering device. Correlation coefficients and regression equations were developed between each instrument and bulk density values as determined with soil cores. The volumeasure had the lowest correlation with soil core bulk density while the air permeameter and proving ring penetrometer had the highest correlation. The gamma ray scattering device was inversely correlated with soil core bulk density.

All readings of the instruments were affected by soil moisture and plant roots. Each instrument has certain advantages and disadvantages. The proving ring penetrometer has the advantage of being moderately correlated $(r=0.86)$ with soil core bulk density plus speed and ease of taking readings. A disadvantage of this instrument is the small area sampled by the cone. Advantages of the pocket penetrometer are that readings can be taken quickly and that the instrument is simple to use. This instrument, however, has limitations on a crusted soil surface; the scale has a limited range of values; a shallow depth and extremely small area of soil is sampled; and spring fatigue is possible. The air permeameter is moderately correlated ( $r=$ 0.86 ) with soil core bulk density, and readings can be taken quickly and with ease. Inaccuracies in readings with the air permeameter result from improper contact of flange on the soil surface and disturbing of soil in the soil cup. The volumeasure has practical use on very thin or rocky soils. The operation of this instrument, however, is time consuming and there is always the possibility of puncturing the balloon. An advantage of using the gamma ray scattering device is the capability of the instrument for taking soil compaction measurements at various depths without greatly disturbing the sampling site. Possible errors in the readings with this instrument are (1) need for correction for soil moisture, (2) difficulty of field calibration, (3) incapability of instrument to make measurements at the $5-\mathrm{cm}$ depth, and (4) presence of minute air pockets under the detector plate.

The air permeameter and proving ring penetrometer are the most promising instruments for measuring soil compaction on rangeland soils because they have the highest correlations with soil core bulk density; readings can be made in a few seconds; and they are lightweight and mobile, easy to operate, and inexpensive. These two instruments were tested on a loamy rangeland soil that was subjected to grazing by livestock near Eureka, Utah. Readings from the two instruments were con- verted to predicted bulk densities using the regression equations. When the predicted values were compared to soil core bulk density, the average deviation of both instruments was 0.049 gms/cc.

\section{Literature Cited}

Andrews, L. A., and W. M. Broadfoot. 1957. The San Dimas soil core sampler. Soil Sci. 85:297-301.

Beckett, S. H. 1928. The use of highly viscous fluids in the determination of volume weight of soils. Soil Sci. 25:481-483.

Carter, L. M. 1967. Portable recording penetrometer measures soil strengths profiles. Agr. Eng. 48:348-349.

Coile, T. S. 1936. Soil samplers. Soil Sci. 42:139-142.

Curry, A. S. 1931. A comparison of methods for determining the volume weight of soils. J. Agr. Res. 42:765-772.

Evans, D. D., and D. Kirkham. 1949. Measurement of the air permeability of soil in situ. Soil Sci. Soc. Amer. Proc. 14:65-73.

Fox, W. E., and D. S. Page-Hanify. 1959. A method of determining bulk density of soil. Soil Sci. 88:168-171.

Isrealson, $\mathbf{O}$. W. 1918. Studies on capacities of soil for irrigation water and on a new method of determining volume weight. J. Agr. Res. 13:1-35.

Jamison, V. C., H. A. Weaver, and I. F. Reed. 1950. A hammer driven soil core sampler. Soil Sci. 69:487-496.

Lutz, J. H. 1944. Determination of certain physical properties of forest soils: I. Methods of utilizing samples in metal cylinders. Soil Sci. 57:475-487.

McLintock, T.F. 1959. Method for obtaining soil sample volumes in the stony soils. J. Forestry 57:832-834.

Phillips, R. E. 1960. Use of radiation equipment for plow layer density and moisture. Soil Sci. 89:2-7.

Phillips, R. E., and D. A. Brown. 1966. Counterdiffusion of $\mathrm{Rb}^{86}$ and $\mathrm{SR}^{89}$ in compacted soil. J. Soil Sci. 17:200-211.

Phillips, R. E., C. R. Jensen, and D. Kirkham. 1959. Use of radiation for plow layer density and moisture. Soil Sci. 89:2-7.

Richards, S. J. 1941. A soil penetrometer. Soil Sci. Soc. Amer. Proc 6:104-107.

Russell, E. W., and W. Balcerck. 1944. The determination of the volume and air space of clods. J. Agr. Sci. 34:123-132.

Shaw, B. T., J. R. Haise, and R. B. Farnsworth. 1942. Four years' experience with a soil penetrometer. Soil Sci. Soc. Amer. Proc. 7:48-55.

Smith, H. W. 1951. Kelley soil sampler in the teaching program. Agron. J 43:617-618.

Smith, I. L., and E. R. Lawson. 1959. Sampler for gravelly plastic soils. Soil Sci. 88:56.

Steinbrenner, E. C. 1959. A portable air permeameter for forest soils. Soil Sci. Soc. Amer. Proc. 23:478-481.

Tanner, C. B., and R. W. Wengel. 1957. Air permeameter for field and laboratory use. Soil Sci. Soc. Amer. Proc. 21:663-664.

Taylor, D. and M. Kansara. 1967. Theory of the nuclear densimeter. Soil Sci. 104:25-34.

Terry, C. W., and H. M. Wilson. 1953. Soil penetrometer in soil compaction studies. Agr. Eng. 34:831-834.

Thompson, J. R. 1968. Effect of grazing on infiltration in a western watershed J. Soil and Water Conserv. 23:63-65.

Torstensson, G., and S. A. Erickson. 1936. A new method for determination of the porosity of the soil. Soil Sci. 42:405-417.

Tueller, P. T. 1962. Plant succession on two Artemisia habitat types in Southeastern Oregon. Unpublished $\mathrm{PhD}$ Diss. Oregon State Univ. Library, Corvallis

Van Bavel, G. H. M., N. Underwood, and S. R. Rogar. 1957. Transmission of gamma rays by soil and soil densiometry. Soil Sci. Soc. Amer. Proc. 21:588-591.

Van Groenewoud, H. 1960. Methods and samplers for obtaining undisturbed soil samples in the forest. Soil Sci. 90:272-274.

Vomocil, J. A. 1954a. In situ measurements of bulk density of soil by gamma ray absorption technique. Soil Sci. 77:341-342.

Vomocil, J. A. 1954b. In situ measurements of soil bulk density. Agr. Eng. 35:651-654.

Vomocil, J. A. 1957. Measurement of soil bulk density and penetrability: Review of methods. Advance in Agron. 9:159-175.

Watson, J. R. 1951. Soil compaction determinations with a soil penetrometer as compared with the Geiger counter $x$-ray spectrometer. Agron. J. 43: 255-258.

Wilde, S. A., and E. C. Steinbrenner. 1950. Determination of air permeability of soil by means of a sphygmomanometer. J. Forestry 43:840-841.

Zwolinski, M., and P. B. Rowe. 1966. Volume weight soil sampler. J. Forestry 64:254-255. 